\title{
The increase in intramyocellular lipid content is a very early response to training
}

Citation for published version (APA):

Schrauwen-Hinderling, V. B., Schrauwen, P., Hesselink, M. K. C., van Engelshoven, J. M. A., Nicolay, K., Saris, W. H. M., Kessels, A. G., \& Kooi, M. E. (2003). The increase in intramyocellular lipid content is a very early response to training. Journal of Clinical Endocrinology \& Metabolism, 88(4), 1610-1616. https://doi.org/10.1210/jc.2002-021464

Document status and date:

Published: 01/01/2003

DOI:

10.1210/jc.2002-021464

Document Version:

Publisher's PDF, also known as Version of record

\section{Please check the document version of this publication:}

- A submitted manuscript is the version of the article upon submission and before peer-review. There can be important differences between the submitted version and the official published version of record.

People interested in the research are advised to contact the author for the final version of the publication, or visit the DOI to the publisher's website.

- The final author version and the galley proof are versions of the publication after peer review.

- The final published version features the final layout of the paper including the volume, issue and page numbers.

Link to publication

\footnotetext{
General rights rights.

- You may freely distribute the URL identifying the publication in the public portal. please follow below link for the End User Agreement:

www.umlib.nl/taverne-license

Take down policy

If you believe that this document breaches copyright please contact us at:

repository@maastrichtuniversity.nl

providing details and we will investigate your claim.
}

Copyright and moral rights for the publications made accessible in the public portal are retained by the authors and/or other copyright owners and it is a condition of accessing publications that users recognise and abide by the legal requirements associated with these

- Users may download and print one copy of any publication from the public portal for the purpose of private study or research.

- You may not further distribute the material or use it for any profit-making activity or commercial gain

If the publication is distributed under the terms of Article $25 \mathrm{fa}$ of the Dutch Copyright Act, indicated by the "Taverne" license above, 


\title{
The Increase in Intramyocellular Lipid Content Is a Very Early Response to Training
}

\author{
V. B. SCHRAUWEN-HINDERLING, P. SCHRAUWEN, M. K. C. HESSELINK, \\ J. M. A. van ENGELShOVEN, K. NICOLAY, W. H. M. SARIS, A. G. H. KESSELS, and M. E. KOOI
}

Department of Radiology (V.B.S.-H., J.M.A.v.E., M.E.K.), University Hospital Maastricht, 6229 HX Maastricht, The Netherlands; Nutrition and Toxicology Research Institute Maastricht (V.B.S.-H., P.S., M.K.C.H., W.H.M.S.), and Departments of Human Biology (P.S., W.H.M.S.) and Movement Sciences (M.K.C.H.), Maastricht University, 6200 MD Maastricht, The Netherlands; Department of Biomedical Engineering (V.B.S.-H., K.N.), Eindhoven University of Technology, 5612 AZ Eindhoven, The Netherlands; and Department of Clinical Epidemiology and Medical Technology Assessment (A.G.H.K.), University Hospital Maastricht, 6229 HX Maastricht, The Netherlands

The present study investigated the influences of a 2-wk training program on intramyocellular lipid (IMCL) content, IMCL decrease during exercise, fat oxidation, and insulin sensitivity.

Nine untrained men (age, $23.3 \pm 3.2 \mathrm{yr}$; body mass index, $22.6 \pm 2.6 \mathrm{~kg} / \mathrm{m}^{2}$; maximal power output, $3.8 \pm 0.6 \mathrm{~W} / \mathrm{kg}$ body weight) trained for 2 wk. Before and after training, subjects cycled for $3 \mathrm{~h}$ while substrate oxidation was measured. IMCL content in the vastus lateralis muscle was determined before and after cycling by proton magnetic resonance spectroscopy. Before and after training, insulin sensitivity was assessed by an insulin tolerance test.

The training period resulted in a significant increase in
IMCL content by $42 \pm 14 \%$. IMCL content decreased significantly during cycling. However, 2 wk of training were not sufficient to achieve increases in fat oxidation and/or use of IMCL during exercise. All markers used to test insulin sensitivity point toward improved insulin sensitivity, albeit not significant. We conclude that the increase in IMCL content is a very early response to training, preceding significant changes in insulin sensitivity. The results suggest that the presence of triglycerides alone does not necessarily have detrimental effects on insulin sensitivity. We confirm earlier reports that IMCL contributes to the energy used during prolonged submaximal exercise. (J Clin Endocrinol Metab 88: 1610-1616, 2003)
$\mathrm{C}^{\mathrm{H}}$ HANGES IN LIFESTYLE over the last few decades have resulted in a dramatic increase in the prevalence of obesity and, consequently, type 2 diabetes worldwide (1). Type 2 diabetes is characterized by perturbations in glucose homeostasis due to decreased insulin sensitivity. Next to disturbances in glucose metabolism, fat metabolism in type 2 diabetes is deranged as well (2). An impairment in fat oxidation (3) and accumulation of im lipids (4) are found in type 2 diabetes. Moreover, strong positive correlations between insulin resistance and IMCL have been reported $(5,6)$. In this context, it is interesting to note that increased IMCL levels are reported in insulin-resistant offspring of type 2 diabetic subjects when compared with matched, insulinsensitive offspring (7), suggesting that a high IMCL content might be involved in the development of insulin resistance.

Strikingly, endurance-trained athletes also show increased IMCL levels (8) while being very insulin sensitive. Traininginduced improvements in insulin sensitivity have been observed within $1 \mathrm{wk}$ after the onset of training in healthy sedentary individuals (9-12), whereas little is known about the time span needed to increase im lipid content with training. Therefore, the first aim of this study was to examine whether insulin sensitivity and IMCL content [determined

Abbreviations: EMCL, Extramyocellular lipids; FFA, free fatty acids; ${ }^{1} \mathrm{H}-\mathrm{MRS}$, proton magnetic resonance spectroscopy; IMCL, intramyocellular lipid; ITT, insulin tolerance test; TMA, trimethylammonium compounds; Wmax, maximal power output. by ${ }^{1} \mathrm{H}$-magnetic resonance spectroscopy $\left.\left({ }^{1} \mathrm{H}-\mathrm{MRS}\right)\right]$ are changed in response to a short-term training program.

It is well known that training increases fat oxidation during exercise. We recently showed, using stable isotopes, that the increase in fat oxidation after a 3-month training program was completely accounted for by an increase in oxidation of im triglycerides and/or very low density lipoproteins (13). This suggests that training induces a shift of the source of lipids used for oxidation toward increased use of im triglycerides and/or very low density lipoproteins. However, with the stable isotope technique, it cannot be deduced whether the oxidation of specifically IMCL is increased. Nevertheless, other techniques indicate that trained subjects rely more on IMCL oxidation during exercise than untrained subjects $(8,14)$. Therefore, the second aim of the study was to examine with ${ }^{1} \mathrm{H}$-MRS whether a short-term training program also increases the use of IMCL during exercise. ${ }^{1} \mathrm{H}$-MRS facilitates quantification of IMCL content noninvasively and repeatedly in the same position in the muscle (15) and provides data from a relatively large tissue volume compared with conventional needle muscle biopsies.

\section{Subjects and Methods}

\section{Subjects}

Nine young, untrained, and healthy male subjects [age, $23.3 \pm 3.2 \mathrm{yr}$; maximal power output (Wmax), $3.8 \pm 0.6 \mathrm{~W} / \mathrm{kg}$ ] participated in this study. Subjects were recruited by advertisement and were excluded from participation if they had performed aerobic exercise competitively for more than 3 months or were still exercising on a regular basis. The 
study was approved by the institutional Medical Ethics Committee. Subjects gave their written informed consent after the nature of the procedure was explained.

\section{Experimental protocol}

One week before the experimental trial, an incremental test to determine Wmax was performed; the test was repeated in the week after the experimental trial.

The setup of the trial was as follows (Fig. 1). Days 1-3 formed a standardization period, during which a standardized diet was provided and subjects refrained from exercise. In the afternoon of $d$ 3, a 3-h cycling test was performed; subjects cycled at $40 \%$ of their predetermined Wmax while substrate oxidation was measured by indirect calorimetry, and blood samples were taken every hour. Before and about 15 min after the cycling test, IMCL content in the vastus lateralis muscle was quantified by ${ }^{1} \mathrm{H}-\mathrm{MRS}$. Subjects then participated in a daily training program with alternating days of either $2 \mathrm{~h}$ of endurance training or $45 \mathrm{~min}$ of interval training. Resting days were incorporated on $\mathrm{d} 4$ and 10. Days 15-17 were used as a standardization period, with the same standardization diet as d 1-3 and with subjects refraining from exercise. In the afternoon of $d$ 17 , subjects again cycled for $3 \mathrm{~h}$ at $40 \%$ Wmax, with substrate oxidation being measured and blood samples being taken; again, IMCL content in the vastus lateralis muscle was quantified by ${ }^{1} \mathrm{H}$-MRS before and after exercise. Insulin sensitivity was assessed by an insulin tolerance test (ITT) in the mornings of $\mathrm{d} 2$ and 16, after an overnight fast. To ensure that training-induced alterations in insulin sensitivity were examined rather than the remnant effect of the final training session, the ITT was planned in the morning of $\mathrm{d} 14$, so that there were $48 \mathrm{~h}$ between the last training session and the ITT. The ITT began with sampling of $10 \mathrm{ml}$ of blood to obtain fasting values of blood parameters.

\section{Diets}

The macronutrient composition of the diets was such that $30 \%$ of the energy was consumed as fat, $55 \%$ as carbohydrate, and $15 \%$ as protein.

Subjects were given a fixed amount of food $(1.65 \times$ basal metabolic rate, based on Harris and Benedict equations; Ref. 16) and were asked to eat all of the food provided and nothing else. The diet consisted of breakfast, lunch, ready to use dinner, and snacks.

\section{Procedures}

Body composition. Whole body density was determined by underwater weighing in the morning in the fasted state. Body weight was measured with a digital balance with an accuracy of $0.01 \mathrm{~kg}$ (August Sauter $\mathrm{GmbH}$, Albstadt-Ebingen, Germany, type E1200). Lung volume was measured simultaneously with the helium dilution technique using a spirometer (Volugraph 2000, Mijnhardt, Mannheim, Germany). Percentage body fat was calculated using the equations of Siri (17).

ITT. ITTs were performed as previously described (18) in the fasted state in the morning of $d 2$ and 16. Briefly, the fall in plasma glucose in response to the injection of $0.1 \mathrm{U} / \mathrm{kg}$ body weight human insulin (Actrapid, Novo Nordisk A/S, Bagsvaerd, Denmark) was monitored every
2 min during $16 \mathrm{~min}$. Insulin was injected via a catheter in the antecubital vein, while arterialized blood samples were obtained via a catheter inserted into a dorsal vein of the contra lateral hand, which was warmed in a heated air box at $60 \mathrm{C}$. Because no changes were noted within $4 \mathrm{~min}$ after administration of insulin, the first $4 \mathrm{~min}$ were not considered in the analysis. Linear regression was used to fit a line through the plasma glucose values between 4 and $16 \mathrm{~min}$. The time until half of the glucose had disappeared $\left(t_{1 / 2}\right)$ was calculated and taken as an indicator of insulin resistance. Therefore, insulin-sensitive subjects will have a low $t_{1 / 2}$, whereas insulin-resistant subjects will have a high $t_{1 / 2}$.

Three-hour cycling test. The exercise test consisted of $3 \mathrm{~h}$ of cycling on an electromagnetically braked ergometer at an intensity of $40 \%$ of the predetermined Wmax. During the exercise test, substrate oxidation was measured every $15 \mathrm{~min}$ using indirect calorimetry (Oxycon- $\beta$, Mijnhardt), and blood samples were collected every $60 \mathrm{~min}$. To facilitate the completion of the exercise test, subjects received two 125-ml servings of a maltodextrine drink (Extran Fresh Citrus: 131 kJ, 31 kcal, 7.9 g carbohydrates, $0 \mathrm{~g}$ proteins and lipids per $100 \mathrm{ml}$ ) during the second half of the test (at $\mathrm{t}=90 \mathrm{~min}$ and $135 \mathrm{~min}$.). Subjects were allowed to drink water ad libitum during the whole test. Fat and carbohydrate oxidation were calculated on the basis of the respiratory quotient values according to Peronnet and Massicotte (19).

Training program. From d 5-14, subjects reported to the laboratory daily to follow supervised training sessions on cycle ergometers, except for the resting day on $\mathrm{d} 10$. Training consisted of alternating days of interval and endurance training and always started with $7.5 \mathrm{~min}$ of warming up at $40 \%$ Wmax and ended with 7.5 min of cooling down at $40 \%$ Wmax. On d 5, 7, 9, 11 and 13, cycling interval training was performed, which consisted of 45 min of alternating 3-min intervals at 70\% Wmax and 35\% Wmax. At d 6, 8, 12, and 14, exercise consisted of 35 min at 55\% Wmax, followed by $35 \mathrm{~min}$ at $50 \%$ Wmax, and $35 \mathrm{~min}$ at $45 \%$ Wmax, for a total duration of $120 \mathrm{~min}$.

MRS measurement. Image-guided localized single voxel ${ }^{1} \mathrm{H}-\mathrm{MRS}$ was performed in the vastus lateralis muscle before and immediately after the 3-h cycling test on the test days at the beginning and at the end of the training period. The measurements were performed on a $1.5 \mathrm{~T}$ whole body scanner (Intera, Philips Medical Systems, Best, The Netherlands) with a flexible surface coil wrapped around the upper leg. To ensure that the fibers of the vastus lateralis muscle ran essentially parallel to the external magnetic field, the leg was placed at an angle of about $30^{\circ}$ from the parallel position.

In every subject, voxels were carefully placed at the same position for all four measurements. Care was taken to avoid vascular structures and adipose tissue deposits within the voxel. To reproduce the same voxel position, the longitudinal distance of the voxel from the intercondylar eminence of the knee joint was determined in a coronal image of the upper leg. T2 weighted fast spin-echo MR images consisting of 5 transversal slices were acquired at this position (slice thickness, $5 \mathrm{~mm}$; repetition time/echo time, $2000 / 85 \mathrm{msec}$; echo train length, 12; field-ofview, $210 \mathrm{~mm}$; and matrix size, $256 \times 256$ ). The patterns of the fat distribution were used to verify the longitudinal position and as landmarks to reproduce the voxel position in the transversal plane.

day \begin{tabular}{c|c|c|c|c|c|c|c|c|c|c|c|c|c|c|c|c|c|c|}
1 & 2 & 3 & 4 & 5 & 6 & 7 & 8 & 9 & 10 & 11 & 12 & 13 & 14 & 15 & 16 & 17 \\
\hline rest & rest & test & rest & int & end & int & end & int & rest & int & end & int & end & rest & rest & test \\
\hline diet & diet & diet & & & & & & & & & & & & diet & diet & diet \\
\hline
\end{tabular}
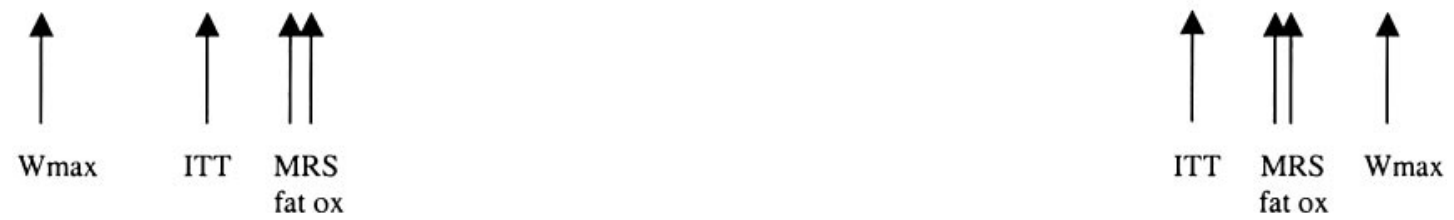

FIG. 1. Scheme of experimental setup. White blocks indicate days without physical exercise, and gray blocks indicate days with physical exercise. The physical exercise consisted of a 3-h cycling test (test) of endurance training (end) or interval training (int). The first $3 \mathrm{~d}$ before a test day consisted of a standardization period with standardized diet. MRS, Quantification of IMCL content by ${ }^{1} \mathrm{H}-\mathrm{MRS}$; fat ox, measurement of fat oxidation during the cycling test by indirect calorimetry. 
${ }^{1} \mathrm{H}-\mathrm{MRS}$ spectra from the regions of interest were acquired using a point-resolved spectroscopy sequence (PRESS) with the following acquisition parameters: repetition time/echo time, $3000 / 25 \mathrm{msec}, 16$ phase cycles, 128 averages, 1024 data points over $1000 \mathrm{~Hz}$ spectral width. The voxel volume was $12 \times 11 \times 18 \mathrm{~mm}^{3}$. The water signal was suppressed using chemically selective saturation (CHESS). The unsuppressed water signal was subsequently measured in the same voxel under the same shimming conditions and was used as a reference signal.

Post processing. The spectra were fitted in the time domain using a nonlinear least-squares algorithm (AMARES; Ref. 20) in the Java-based magnetic resonance user interface (jMRUI) software package (21). Eight peaks were fitted in total, namely two peaks for total creatine and trimethylammonium compounds (TMA), three peaks for extramyocellular lipids (EMCL), and three peaks for IMCL (Fig. 2). Prior knowledge (20) of the relative peak positions (22) and area ratios (personal communication) as determined by Boesch et al. were used as a constraint. The line width of the $\mathrm{CH}_{2}$ peak of IMCL was fixed relative to the line width of the unsuppressed water peak (measured in the same voxel) to increase the accuracy and reliability of the fitting procedure. The line widths of total creatine and TMA compounds were constrained to be equal. All other line widths were unconstrained. IMCL peaks and EMCL peaks were fitted with a Gaussian curve, whereas total creatine, TMA, and water peaks were fitted with a Lorenztian curve. The signals were corrected for $\mathrm{T} 1$ and $\mathrm{T} 2$ relaxation using the $\mathrm{T} 1$ and $\mathrm{T} 2$ relaxation times as determined by Schick et al. (23). The corrected area of the $\mathrm{CH}_{2}$ peak of IMCL was expressed relative to the area of the water peak.

The reproducibility of the quantification of IMCL in the vastus lateralis muscle was determined in the setting of another study by measuring one subject several times, with the subject leaving the scanner table between measurements. From five corresponding pairs of measurements, we calculated an average coefficient of variation of $6.0 \% \pm$ $8.2 \%$ (mean $\pm \mathrm{SD}$; our unpublished results). If total creatine was used as a reference instead of water, the coefficient of variation was larger, namely $11.5 \% \pm 11.9 \%$ (mean $\pm \mathrm{SD})$.

\section{Analysis}

Blood analyses. For determination of free fatty acids (FFA), glycerol, and glucose, blood was collected in tubes containing $30 \mu \mathrm{l}$ of $0.2 \mathrm{M}$ EDTA. Plasma was immediately centrifuged at high speed, frozen in liquid nitrogen, and stored at $-80 \mathrm{C}$ for later analyses. Insulin concentrations were measured using RIA (Linco Research, Inc., St. Charles, MO). FFA were determined using the Wako Nefa C testkit (Wako Pure Chemical Industries Ltd., Neuss, Germany).

Plasma glucose was determined using the hexokinase method (LaRoche, Basel, Switzerland), and glycerol was determined using the GPO-trinder (Sigma, St. Louis, MO).

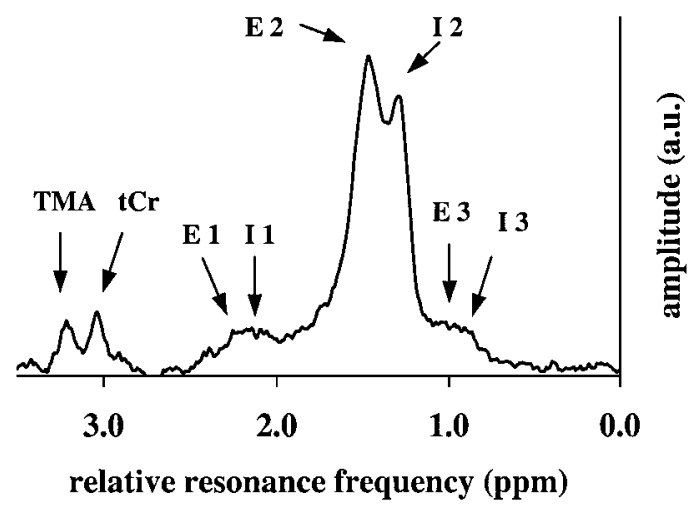

FIG. 2. Typical spectrum of the vastus lateralis muscle. TMA, Trimethyl ammonium compounds; $\mathrm{tCr}$, total creatine; E1, broad peak of various, chemically different methylene protons of EMCL (22); E2, methylene protons of EMCL; E3, methyl protons of EMCL; I1, broad peak of various, chemically different methylene protons of IMCL (22); I2, methylene protons of IMCL; I3, methyl protons of IMCL.
Statistics. Characteristics of subjects and the coefficient of variation of the measurement are reported as mean $\pm \mathrm{SD}$, and results are reported as mean \pm SEM. Statistical analyses were performed with SPSS for Windows 10.0.0 software (SPSS, Inc., Chicago, IL). Differences before and after training were detected with paired Student's $t$ tests. The blood parameters during exercise were analyzed with a general linear model repeated measures analyses. If the repeated measures analyses detected significant differences, post hoc $t$ tests were performed. Asterisks in the figures indicate significant differences according to the $t$ tests. Results were considered significant if $P$ values were less than 0.05 .

\section{Results}

\section{Maximal performance}

Maximal performance did not change significantly due to the training program $(272.8 \pm 14.0 \mathrm{~W}$ vs. $281.7 \pm 13.4 \mathrm{~W}$ before and after training, respectively).

\section{Substrate oxidation}

Fat oxidation gradually increased during the 3-h cycling test (Fig. 3A). During the first $90 \mathrm{~min}$ (before the carbohy-
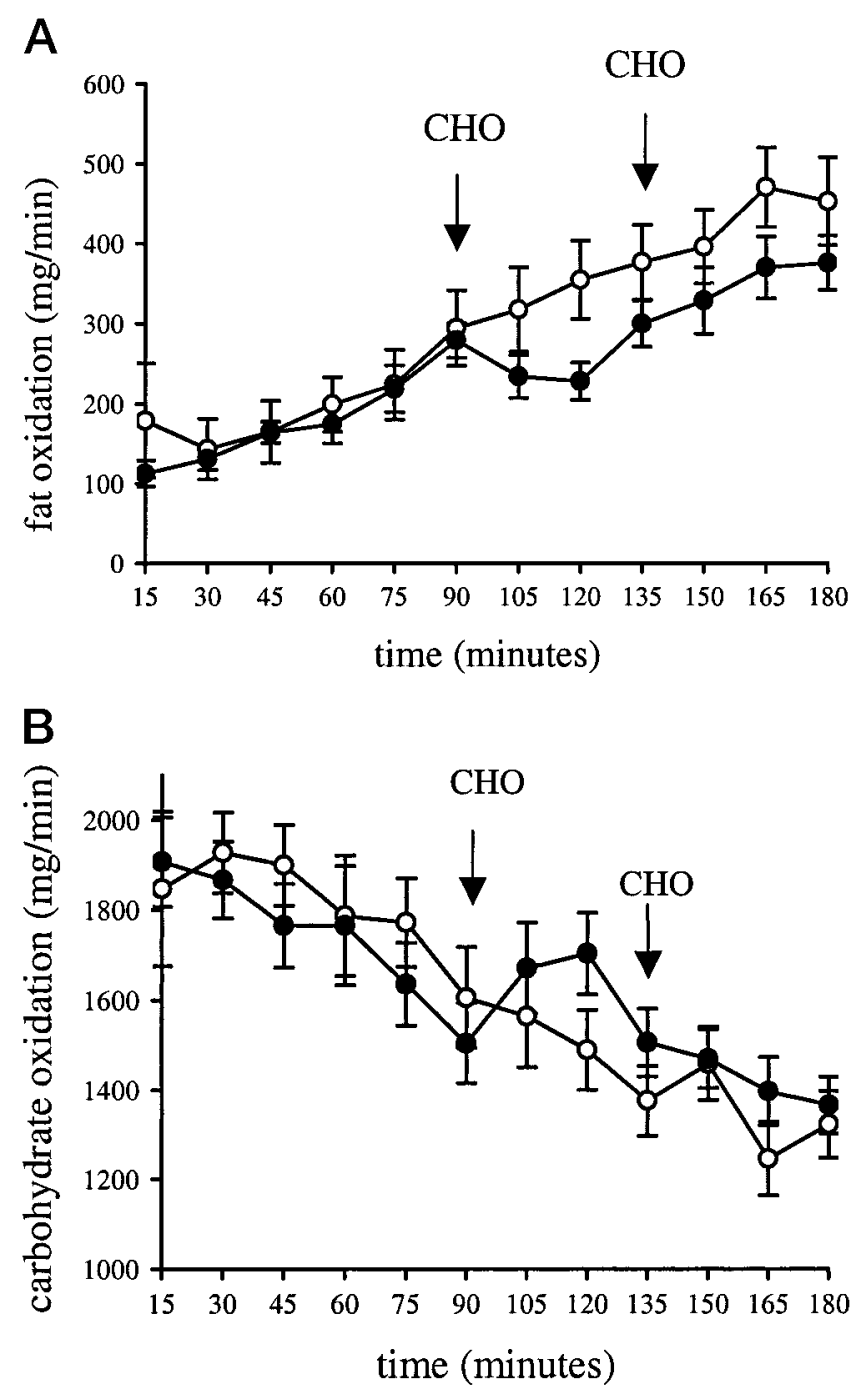

FIG. 3. Fat oxidation (A) and carbohydrate oxidation (B) were measured every $15 \mathrm{~min}$ by indirect calorimetry during the 3 -h cycling test. Open circles, before training; filled circles, after training. Arrows indicate the gavage of a carbohydrate $(\mathrm{CHO})$ drink. 
drate drink), fat oxidation before and after training did not differ significantly. After training, a decrease in fat oxidation was observed at $\mathrm{t}=90 \mathrm{~min}$. This coincided with the administration of a carbohydrate drink. As a consequence, a significantly lower fat oxidation was observed after training compared with before training in the second $90 \mathrm{~min}$ of the test. The average fat oxidation over the entire $180 \mathrm{~min}$ of the test was not significantly different after training.

Reciprocal effects were observed for carbohydrate oxidation (Fig. 3B). During the first 90 min (before the carbohydrate drink), carbohydrate oxidation before and after training did not differ significantly. When the carbohydrate drink was administered, carbohydrate oxidation increased after training but not before training. As a consequence, a significantly higher carbohydrate oxidation was observed after training compared with before training in the second $90 \mathrm{~min}$ of the test. The average carbohydrate oxidation over the entire $180 \mathrm{~min}$ of the test was not significantly different after training.

\section{Blood parameters}

There were no significant differences before and after training in the fasting plasma values of insulin [7.46 \pm 1.10 vs. $7.44 \pm 1.12 \mu \mathrm{U} / \mathrm{ml}$ (mU/liter)], FFA (355.28 \pm 48.34 $\mu \mathrm{mol} /$ liter vs. $349.11 \pm 46.62 \mu \mathrm{mol} /$ liter $)$, and glycerol (67.99 $\pm 6.03 \mu \mathrm{mol} /$ liter vs. $71.00 \pm 6.05 \mu \mathrm{mol} /$ liter $)$. However, there was a tendency of decreased fasting plasma glucose after training $(5.23 \pm 0.08 \mathrm{mmol} /$ liter vs. $5.07 \pm 0.11$ mmol/liter; $P=0.062$ ).

During exercise, there was a significant effect of time for insulin, with values decreasing with time $(P<0.001)$, but no treatment (training) or treatment $\times$ time interaction effect (Fig. 4A). There was a significant effect of time $(P<0.001)$, treatment, and time $\times$ treatment interaction for FFA plasma values, with values increasing with time (Fig. 4B). After training, values were lower than before training in the second half of the cycling test. For glycerol plasma concentrations, there was a time effect $(P<0.001)$, a treatment effect, and a time $\times$ treatment interaction effect. Glycerol concentrations increased gradually during the test. In the second half of the exercise test, concentrations were lower after training compared with before training (Fig. 4C). There was a significant effect of time for glucose plasma values, with values decreasing with time, a tendency for a treatment effect with levels being higher after training $(P=0.07)$, and no treatment $\times$ time interaction effect (Fig. 4D).

\section{$I T T$}

After training, there was a tendency for the plasma glucose to drop faster in response to insulin. The $t_{1 / 2}$ of glucose disappearance tended to be shorter after training compared with before training $(15.4 \pm 1.4 \mathrm{~min}$ vs. $14.1 \pm 1.1 \mathrm{~min}$; $P=0.12)$.

\section{IMCL content}

Spectra from identical voxel positions at all four points in time were available from seven subjects. Before training, preexercise IMCL content was $0.35 \pm 0.02 \%$ of the water reference signal. Training increased the preexercise IMCL
FIG. 4. Blood plasma parameters during the 3-h cycling test. Open symbols, before training; filled symbols, after training. *, Significant differences between pre- and posttraining values. A, Insulin plasma concentrations; B, FFA plasma concentrations; C, glycerol plasma concentrations; $\mathrm{D}$, glucose plasma concentrations.

\section{A}

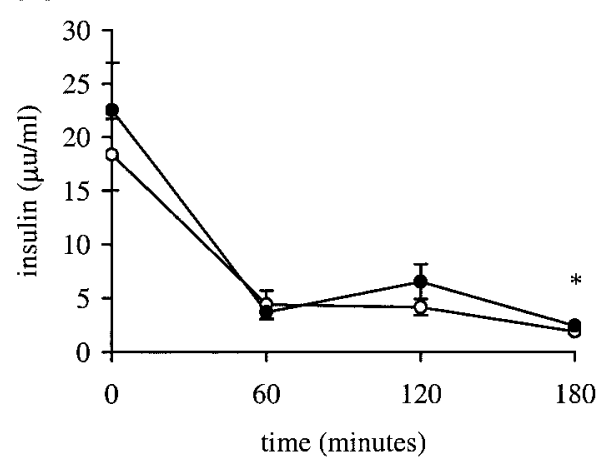

C

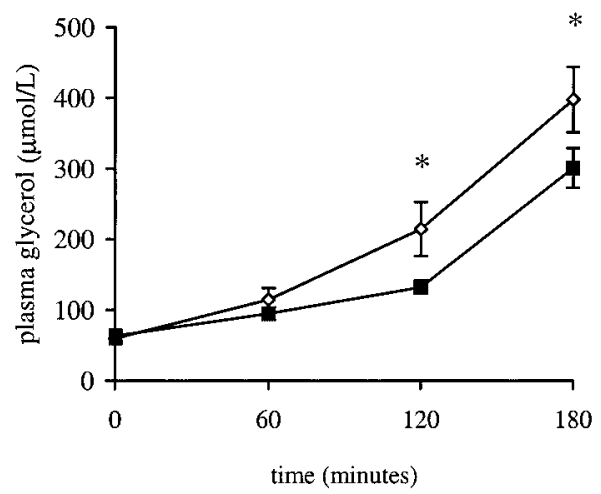

B

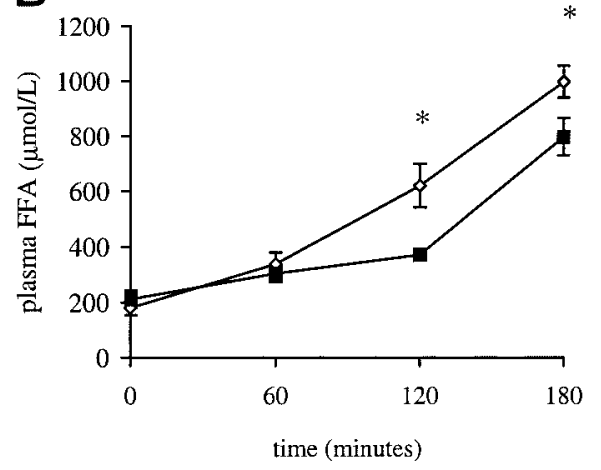

D

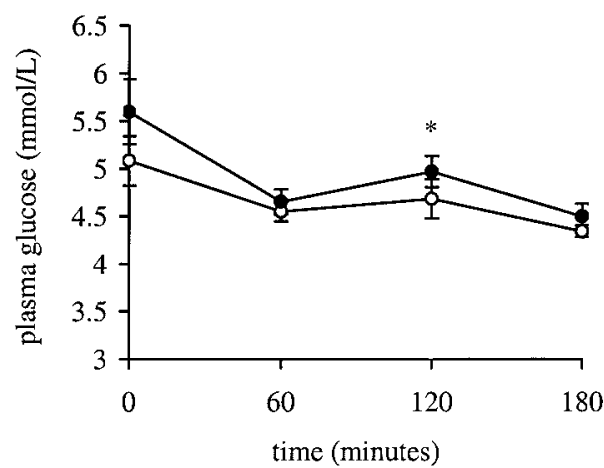




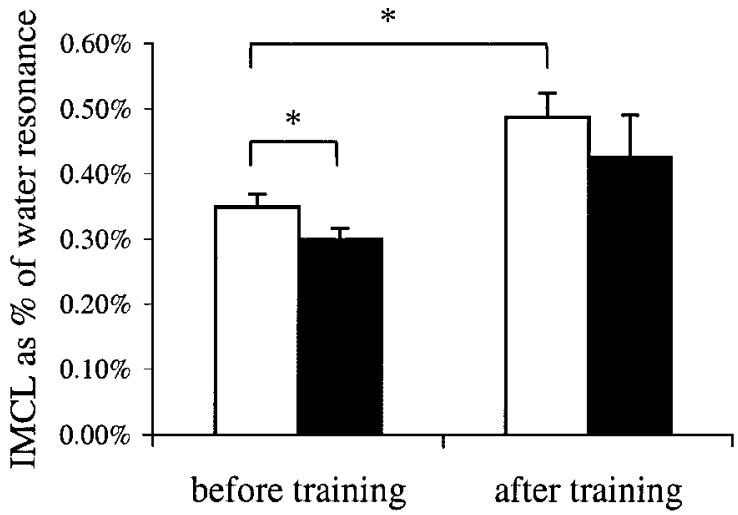

FIG. 5. IMCL content, expressed as percentage of the water resonance. White bars, before cycling test; black bars, after cycling test. *, Significant differences.

content significantly by $42 \pm 14 \%$ (Fig. 5 ). Before training, the 3-h cycling test decreased the IMCL signal by $14 \pm 3 \%(P<$ $0.01)$. After training, the decrease in IMCL content during the 3 -h cycling test was similar $(14 \% \pm 9 \%)$, but this decrease did not reach significance (Fig. 5). If total creatine was used as reference instead of water, similar results were obtained: a significant increase in IMCL with training, a significant depletion during cycling before training, and a (nonsignificant) depletion during cycling after training.

Insulin sensitivity did not correlate with IMCL content in this small group, either before or after training.

\section{Discussion}

The most important finding of the present study is that the IMCL content is increased significantly after a training period of as short as $2 \mathrm{wk}$. During this period, no significant changes in fat oxidation or insulin sensitivity were detected. From this, we conclude that the increase in IMCL content is among the earliest responses to training. Furthermore, the results of the present study suggest that the presence of triglycerides alone in myocytes does not have detrimental effects on insulin sensitivity. Also, we confirm earlier reports that IMCL contribute to the energy used during prolonged submaximal exercise.

It is generally accepted that training improves insulin sensitivity, and it has previously been shown that training can increase insulin sensitivity after a period of training as short as $7 \mathrm{~d}(9-12)$, although it cannot be excluded that some remnant effect of the last exercise bout was detected in these studies. In the present study, insulin sensitivity was not yet significantly increased. This lack of increase can be due to different indicators of insulin sensitivity used or to different training protocols used (18). We chose to use the ITT, which measures the hypoglycemic action of injected insulin, because it is a short test that has recently been shown to be sensitive enough to detect differences in the improvement in insulin sensitivity induced by different training programs (18). Although the increase in insulin sensitivity as quantified by the ITT was not significant $(P=0.12)$, we did find some indication of increased insulin action. There was a tendency for fasted glucose levels to be lower by $3 \%(P=0.062)$, whereas insulin levels were unchanged. Furthermore, an oral carbohydrate load, administered in the second half of the exercise test to facilitate the completion of the test, led to an increase in carbohydrate oxidation observed solely after training. In accordance with this, the carbohydrate load resulted in reduced lipolysis and fat oxidation after training in the second part of the test. These changes could indicate improved glucose absorption and disposal. It has been described that exogenous carbohydrate oxidation is higher in trained subjects (24) and that a training intervention of $12 \mathrm{wk}$ can stimulate oxidation of exogenous glucose (25); this could indicate an increased insulin sensitivity. Furthermore, shortterm training has been reported to increase GLUT-4 content (26) and hexokinase activity $(27,28)$, indicating improved glucose disposal capacity. Alternatively, changes in perfusion of splanchnic system occur with training (29) and may induce increased absorption of glucose and contribute to the increased oxidation after an oral glucose load. Future studies should address the mechanism of increased glucose oxidation after an oral glucose load in trained vs. untrained subjects in more detail.

The positive correlations of IMCL content with insulin resistance that were reported in different populations $(5,6)$ and the finding that the increase in IMCL content precedes the development of diabetes $(7,30)$ suggest that im lipids might be involved in the development of insulin resistance. However, the finding that IMCL content is also increased in highly trained, insulin-sensitive athletes $(8,31,32)$ and that their IMCL contents are actually very similar to those reported in diabetic subjects is paradoxical and favors a more complex explanation (33). In the present study, we find an increase in IMCL, which is not coupled to a diminished insulin sensitivity; rather, we find indications of improved insulin sensitivity. Therefore, the results of the present study suggest that it is unlikely that the presence of triglycerides alone in myocytes is leading to a decrease in insulin sensitivity. Also, other authors have suggested that an interference of lipid degradation-derived intermediates such as long chain acyl-coenzyme A and diacylglycerol with insulin signaling (34-37) would be more likely than the triglycerides themselves to be responsible for disturbed insulin action.

We showed earlier that the increase in fat oxidation during exercise due to long-term training can be completely accounted for by increased oxidation of triglyceride-derived fatty acids (13). Therefore, and also based on earlier results from biochemical analyses of biopsies, it has been suggested that training might lead to an increased oxidation of im lipids during exercise (14). Others, however, found no changes in im lipid oxidation with training (38). In the current study, we confirm earlier results that showed that IMCL decrease during exercise $(15,39)$. However, the decrease in IMCL after $3 \mathrm{~h}$ of exercise was similar before and after training, suggesting that the use of IMCL was not altered with training. However, it is important to note that total fat oxidation over the $3 \mathrm{~h}$ was not changed after training. Furthermore, we cannot exclude that the improved use of carbohydrate after training, which reduced fat oxidation in the second part of the exercise test, could have interfered with a decrease of IMCL content after training.

There has been some concern about using the water signal as a reference after exercise because water and electrolyte 
shifts are possible. When using total creatine instead of water as internal standard in the current study, we found no statistical difference between the results using the two methods. In both cases, we found a significant IMCL depletion before training, a nonsignificant depletion after training, and significant training-induced increase in baseline IMCL. We chose to use the water peak as internal reference, because the use of the small peak of total creatine introduced some additional variability so that the average coefficient of variation of repeated measurements increased from an average of $6 \%$ with water to $11.5 \%$ with total creatine. Because no trends in water signal or the water to total creatine signal ratio were found before $v s$. after exercise, we feel that it is justified to use the water signal as the internal standard in the present study.

It has been shown that training can lead to an increase in fat oxidation after $7 \mathrm{~d}$ of endurance training (40). The finding that fat oxidation during the first 90 min (before any carbohydrate was administered) did not increase with the current protocol could be due to the nature of the training protocol, which consisted of endurance as well as high intensity components. It is assumed that the current exercise protocol was too short to produce increases in fat oxidation in untrained subjects. In conclusion, we showed in the present study that in untrained subjects, IMCL content was increased with training before an adaptation in fat oxidation occurred and that the increase in IMCL content was not coupled to a decrease in insulin sensitivity. Rather, we find indications of improved insulin sensitivity. These results suggest that the presence of IMCL alone does not hamper insulin sensitivity. Instead, the data are in line with models that suggest a more indirect relationship between IMCL content and insulin resistance, e.g. models that suggest that accumulation of intermediates of fat oxidation might interfere with insulin signaling (34-37). More studies are needed to investigate these mechanisms in detail.

\section{Acknowledgments}

We thank Steven Constandse and Niels Boon for their help in performing this study.

Received September 18, 2002. Accepted December 30, 2002.

Address all correspondence and requests for reprints to: Vera B. Schrauwen-Hinderling, Department of Radiology, University Hospital Maastricht, P.O. Box 5800, 6202 AZ Maastricht, The Netherlands. E-mail: vhi@rdia.azm.nl.

P.S. was supported by a grant from the Netherlands Organization for Scientific Research.

\section{References}

1. Zimmet P, Alberti KG, Shaw J 2001 Global and societal implications of the diabetes epidemic. Nature 414:782-787

2. Colberg SR, Simoneau JA, Thaete FL, Kelley DE 1995 Skeletal muscle utilization of free fatty acids in women with visceral obesity. J Clin Invest 95: $1846-1853$

3. Blaak EE, van Aggel-Leijssen DP, Wagenmakers AJ, Saris WH, van Baak MA 2000 Impaired oxidation of plasma-derived fatty acids in type 2 diabetic subjects during moderate-intensity exercise. Diabetes 49:2102-2107

4. Levin K, Daa Schroeder H, Alford FP, Beck-Nielsen H 2001 Morphometric documentation of abnormal intramyocellular fat storage and reduced glycogen in obese patients with Type II diabetes. Diabetologia 44:824-833

5. Krssak M, Falk Petersen K, Dresner A, DiPietro L, Vogel SM, Rothman DL, Roden M, Shulman GI 1999 Intramyocellular lipid concentrations are correlated with insulin sensitivity in humans: a 1H NMR spectroscopy study. Diabetologia 42:113-116

6. Pan DA, Lillioja S, Kriketos AD, Milner MR, Baur LA, Bogardus C, Jenkins
AB, Storlien LH 1997 Skeletal muscle triglyceride levels are inversely related to insulin action. Diabetes 46:983-988

7. Jacob S, Machann J, Rett K, Brechtel K, Volk A, Renn W, Maerker E, Matthaei S, Schick F, Claussen CD, Haring HU 1999 Association of increased intramyocellular lipid content with insulin resistance in lean nondiabetic offspring of type 2 diabetic subjects. Diabetes 48:1113-1119

8. Decombaz J, Schmitt B, Ith M, Decarli B, Diem P, Kreis R, Hoppeler H, Boesch C 2001 Postexercise fat intake repletes intramyocellular lipids but no faster in trained than in sedentary subjects. Am J Physiol Regul Integr Comp Physiol 281:R760-R769

9. Houmard JA, Shaw CD, Hickey MS, Tanner CJ 1999 Effect of short-term exercise training on insulin-stimulated PI 3-kinase activity in human skeletal muscle. Am J Physiol 277:E1055-E1060

10. Cox JH, Cortright RN, Dohm GL, Houmard JA 1999 Effect of aging on response to exercise training in humans: skeletal muscle GLUT-4 and insulin sensitivity. J Appl Physiol 86:2019-2025

11. Youngren JF, Keen S, Kulp JL, Tanner CJ, Houmard JA, Goldfine ID 2001 Enhanced muscle insulin receptor autophosphorylation with short-term aerobic exercise training. Am J Physiol Endocrinol Metab 280:E528-E533

12. Tanner CJ, Koves TR, Cortright RL, Pories WJ, Kim YB, Kahn BB, Dohm GL, Houmard JA 2002 Effect of short-term exercise training on insulin-stimulated PI 3-kinase activity in middle-aged men. Am J Physiol Endocrinol Metab 282:E147-E153

13. Schrauwen P, van Aggel-Leijssen DP, Hul G, Wagenmakers AJ, Vidal H, Saris WH, van Baak MA 2002 The effect of 3 month low intensity endurance training on fat oxidation and acetyl-CoA carboxylase-2 expression. Diabetes 51:2220-2226

14. Hurley BF, Nemeth PM, Martin 3rd WH, Hagberg JM, Dalsky GP, Holloszy JO 1986 Muscle triglyceride utilization during exercise: effect of training. J Appl Physiol 60:562-567

15. Boesch C, Decombaz J, Slotboom J, Kreis R 1999 Observation of intramyocellular lipids by means of $1 \mathrm{H}$ magnetic resonance spectroscopy. Proc Nutr Soc 58:841-850

16. Harris JA, Benedict FG 1919 A biometric study of basal metabolism in man. Washington, DC: Carnegie Institution of Washington

17. Siri W 1956 The gross composition of the body. Adv Biol Med Physiol 4: 239-280

18. Borghouts LB, Backx K, Mensink MF, Keizer HA 1999 Effect of training intensity on insulin sensitivity as evaluated by insulin tolerance test. Eur J Appl Physiol Occup Physiol 80:461-466

19. Peronnet F, Massicotte D 1991 Table of nonprotein respiratory quotient: an update. Can J Sport Sci 16:23-29

20. Vanhamme L, van den Boogaart A, Van Huffel S 1997 Improved method for accurate and efficient quantification of MRS data with use of prior knowledge. J Magn Reson 129:35-43

21. Naressi A, Couturier C, Devos JM, Janssen M, Mangeat C, de Beer R, Graveron-Demilly D 2001 Java-based graphical user interface for the MRUI quantitation package. Magma 12:141-152

22. Boesch C, Slotboom J, Hoppeler H, Kreis R 1997 In vivo determination of intra-myocellular lipids in human muscle by means of localized ${ }^{1} \mathrm{H}-\mathrm{MR}$ spectroscopy. Magn Reson Med 37:484-493

23. Schick F, Eismann B, Jung WI, Bongers H, Bunse M, Lutz O 1993 Comparison of localized proton NMR signals of skeletal muscle and fat tissue in vivo: two lipid compartments in muscle tissue. Magn Reson Med 29:158-167

24. Burelle Y, Peronnet F, Charpentier S, Lavoie C, Hillaire-Marcel C, Massicotte D 1999 Oxidation of an oral [13C] glucose load at rest and prolonged exercise in trained and sedentary subjects. J Appl Physiol 86:52-60

25. Krzentowski G, Pirnay F, Luyckx AS, Lacroix M, Mosora F, Lefebvre PJ 1984 Effect of physical training on utilization of a glucose load given orally during exercise. Am J Physiol 246:E412-E417

26. Phillips SM, Han XX, Green HJ, Bonen A 1996 Increments in skeletal muscle GLUT-1 and GLUT-4 after endurance training in humans. Am J Physiol 270: E456-E462

27. Phillips SM, Green HJ, Tarnopolsky MA, Heigenhauser GJ, Grant SM 1996 Progressive effect of endurance training on metabolic adaptations in working skeletal muscle. Am J Physiol 270:E265-E272

28. Coggan AR, Kohrt WM, Spina RJ, Bier DM, Holloszy JO 1990 Endurance training decreases plasma glucose turnover and oxidation during moderateintensity exercise in men. J Appl Physiol 68:990-996

29. Lash JM 1998 Training-induced alterations in contractile function and excitation-contraction coupling in vascular smooth muscle. Med Sci Sports Exerc 30:60-66

30. Malenfant $P$, Tremblay A, Doucet E, Imbeault P, Simoneau JA, Joanisse DR 2001 Elevated intramyocellular lipid concentration in obese subjects is not reduced after diet and exercise training. Am J Physiol Endocrinol Metab 280:E632-E639

31. Morgan TE, Short FA, Cobb LA 1969 Effect of long-term exercise on skeletal muscle lipid composition. Am J Physiol 216:82-86

32. Hoppeler H, Howald H, Conley K, Lindstedt SL, Claassen H, Vock P, Weibel ER 1985 Endurance training in humans: aerobic capacity and structure of skeletal muscle. J Appl Physiol 59:320-327 
33. Goodpaster BH, He J, Watkins S, Kelley DE 2001 Skeletal muscle lipid content and insulin resistance: evidence for a paradox in endurance-trained athletes. J Clin Endocrinol Metab 86:5755-5761

34. Laybutt DR, Schmitz-Peiffer C, Saha AK, Ruderman NB, Biden TJ, Kraegen EW 1999 Muscle lipid accumulation and protein kinase C activation in the insulin-resistant chronically glucose-infused rat. Am J Physiol 277:E1070E1076

35. Ellis BA, Poynten A, Lowy AJ, Furler SM, Chisholm DJ, Kraegen EW, Cooney GJ 2000 Long-chain acyl-CoA esters as indicators of lipid metabolism and insulin sensitivity in rat and human muscle. Am J Physiol Endocrinol Metab 279:E554-E560

36. Dobbins RL, Szczepaniak LS, Bentley B, Esser V, Myhill J, McGarry JD 2001 Prolonged inhibition of muscle carnitine palmitoyltransferase-1 promotes intramyocellular lipid accumulation and insulin resistance in rats. Diabetes 50:123-130
37. Itani SI, Ruderman NB, Schmieder F, Boden G 2002 Lipid-induced insulin resistance in human muscle is associated with changes in diacylglycerol, protein kinase $\mathrm{C}$, and I $\kappa \mathrm{B}-\alpha$. Diabetes 51:2005-2011

38. Bergman BC, Butterfield GE, Wolfel EE, Casazza GA, Lopaschuk GD, Brooks GA 1999 Evaluation of exercise and training on muscle lipid metabolism. Am J Physiol 276:E106-E117

39. Krssak M, Petersen KF, Bergeron R, Price T, Laurent D, Rothman DL, Roden M, Shulman GI 2000 Intramuscular glycogen and intramyocellular lipid utilization during prolonged exercise and recovery in man: a $13 \mathrm{C}$ and $1 \mathrm{H}$ nuclear magnetic resonance spectroscopy study. J Clin Endocrinol Metab 85:748-754

40. Putman CT, Jones NL, Hultman E, Hollidge-Horvat MG, Bonen A, McConachie DR, Heigenhauser GJ 1998 Effects of short-term submaximal training in humans on muscle metabolism in exercise. Am J Physiol 275:E132-E139 